\title{
O PROCESSO DE DESCARTE DE LIVROS DIDÁTICOS: UMA PERSPECTIVA EM DUAS INSTITUIÇÕES DE ENSINO NORTE-RIO-GRANDENSES
}

\author{
Jéssica Sibelly Mendonça da Silva (INSTITUTO FEDERAL DE EDUCAÇÃO, CIÊNCIA E \\ TECNOLOGIA DO RIO GRANDE DO NORTE) jessicasibelly4@ gmail.com \\ Letícia Fernanda da Silva Lucas (INSTITUTO FEDERAL DE EDUCAÇÃ̃O, CIÊNCIA E \\ TECNOLOGIA DO RIO GRANDE DO NORTE) leticiawyster15@gmail.com \\ Rony Edson da Silva Gonçalves (INSTITUTO FEDERAL DE EDUCAÇÃ̃O, CIÊNCIA E \\ TECNOLOGIA DO RIO GRANDE DO NORTE) ronyedson123@ gmail.com
}

\section{Resumo}

$\mathrm{O}$ artigo tem como objetivo analisar e comparar os livros obsoletos em um campus do Instituto Federal do Rio Grande do Norte e de uma escola técnica estadual, encontrando os erros e os acertos das duas instituições, tanto em relação ao descarte, quanto ao armazenamento do material obsoleto. Utilizou-se um estudo de caso, a partir de dois questionários para a melhor compreensão do assunto tratado e com base nos dados adquiridos constatou-se que o IFRN possui um mau acondicionamento. Diante disso, tornar possível o desenvolvimento de um projeto que possa implementar os conhecimentos para um desfazimento adequado.

Palavras-Chaves: (Descarte, livros didáticos, estoque obsoleto)

\section{Introdução}

As escolas públicas brasileiras têm o direito de receber, para seus estudantes, livros didáticos cuja função é auxiliar o aprendizado. Os discentes recebem o material no início do ano letivo e o entregam ao fim. Esse processo tem o intuito de repassar esses livros no ano seguinte para outro estudante, assim construindo um ciclo de 3 anos para esses objetos.

Pode-se afirmar que em muitas instituições acontece a devolução do material que já cruzou a etapa dos 3 anos e esse, já inutilizável, múltiplas vezes não tem o descarte correto. Ter-se atenção com o estoque obsoleto para que o mesmo seja descartado da maneira correta é primordial.

No Brasil mais de 145 mil escolas são beneficiadas com os livros didáticos. Sua distribuição é realizada de acordo com o Censo Escolar, atualizado em todos os anos letivos e desempenhado pelo Instituto Nacional de Estudos e Pesquisas Educacionais Anísio Teixeira 
(Inep). Entretanto, nem todas as instituições têm conhecimento do descarte correto do material recebido.

Diante dessa situação, o presente artigo tem como alvo analisar e comparar os livros obsoletos em um campus do Instituto Federal do Rio Grande do Norte e de uma escola técnica estadual, encontrando os erros e os acertos das duas instituições, tanto em relação ao descarte, quanto ao armazenamento do material obsoleto.

Sendo assim, o estudo justifica-se pela ausência de conhecimento para o descarte por parte de algumas escolas, exibindo informações imprescindíveis para essa transferência e um estudo de caso para melhor compreensão do assunto tratado, apresentando com clareza a importância do desfazimento adequado.

\section{Referencial teórico}

\subsection{Estoques}

Para Slack, Chambers e Johnston (2009), estoque é definido como a acumulação armazenada de recursos materiais em um sistema de transformação. Essa acumulação encontra-se em qualquer etapa do processo, desde inputs a outputs, ou seja, cada operação realizada produz estoque.

A demanda alternada em diferentes zonas do processo produtivo promove a separação dos tipos de estoque, são eles: Estoque de segurança ou isolador; estoque de ciclo; estoque de antecipação; estoque de desacoplamento; estoques no canal de distribuição.

Sua função é atender de imediato a solicitação da próxima etapa do processo, seja ela de transformação ou consumo final, garantindo dinamismo de modo a evitar ociosidade por parte dos requerentes do material. Diante disso, proporciona a flexibilidade do processo produtivo, sazonalidade no suprimento e assegura o fornecimento de materiais à organização, assim garantindo a realização do estágio seguinte.

Sabe-se que apesar dos benefícios de ter-se estoque, este tipo de acúmulo requer espaço apropriado, uma boa gestão organizacional e manutenções frequentes. Estes quesitos são um grande desafio para muitas organizações, pois a carência de uma boa administração pode acarretar, por exemplo, avarias e obsolescência, ou seja, a perda de uma parcela ou de todo o estoque. 
Para um bom funcionamento, existe a política de estoques, a qual visa demonstrar a conduta que a organização deve seguir para obter sucesso no departamento de estoques. Cada organização estipula suas normas, intentando administrar adequadamente sua aglomeração. $\mathrm{O}$ controle do acúmulo é fundamental, pois determina quando deve haver novo pedido e/ou produção.

\subsection{Vantagens e desvantagens dos estoques}

Possuir um estoque é vantajoso pelo fato de ajudar a tornar possível a prevenção da escassez de materiais na etapa seguinte, desta forma viabilizando a eficiência e flexibilidade do processo produtivo, garante estabilidade nos períodos de maior quantidade de vendas e certifica o abastecimento de peças às organizações.

$\mathrm{O}$ ato de manter um estoque por um longo período é desvantajoso devido o acarretamento de consequências, tais como o comprometimento da integridade dos materiais acumulados, considerando os riscos de avarias, obsolescência e ociosidade. Os custos de manutenção e controle (energia, mão-de-obra, materiais de auxílio, etc.), bem como o capital que permanece inativo enquanto o estoque está parado, são, também, fatores inconvenientes na prática da estocagem.

\subsection{Plano Nacional do Livro Didático (PNLD)}

Foi em agosto de 1985, por intermédio do Decreto-Lei no 91.542, que recebeu a denominação de Programa Nacional do Livro Didático (PNLD), objetivando ampliação do projeto. Estipulou-se como meta o atendimento de todos os alunos de primeira a oitava série do primeiro grau das escolas públicas federais, estaduais, territoriais, municipais e comunitárias do país, com prioridade para os componentes básicos Comunicação e Expressão e Matemática.

As diretrizes do Ministério da Educação quanto à distribuição referem-se à transferência de posse dos livros didáticos, do governo federal (adquirente) para os governos estaduais e municipais, ou seja, o governo federal compra o material e transfere-o para governos estaduais e municipais. Ao acontecer essa transferência, a responsabilidade do descarte dos livros ao término do triênio é dos beneficiários. 
prevê a Resolução ${ }^{\circ}$ 5, de 21 de fevereiro de 2002, do Fundo Nacional de Desenvolvimento da Educação (FNDE/MEC). Assim, as secretarias estaduais e municipais de Educação que querem se desfazer do material devem seguir a legislação local que regulamenta o reaproveitamento, a movimentação, a alienação e outras formas de rejeição de bens públicos. (Portal MEC, 2005).

Toda instituição pública de viés educacional, tem o direito de receber - de maneira gratuita o material do PNLD, ficando a critério da escola a seleção de tais ferramentas ou se irá adquiri-las.

O Ministério da Educação também tem diretrizes quanto ao descarte, mesmo que seja de responsabilidade dos beneficiários. O MEC dá suas orientações quanto ao desfazimento dos livros didáticos fora do triênio ou - como também podem ser nomeados - obsoletos.

Quando o bem pode ser vendido, deve-se optar por concorrência, leilão ou cartaconvite, de acordo com o valor a ser negociado. Os objetos podem ser vendidos em unidades ou em lotes - neste caso, preferencialmente em conjuntos que não devem ser desfeitos. De acordo com o tipo de operação, o edital tem de ser divulgado no Diário Oficial da União de uma a três vezes, em prazos que vão de três dias úteis a 30 dias corridos. (PORTAL MEC, 2005)

Ao término do ciclo de vida dos livros, os estudantes têm o direito de permanecer com o material didático ou devolvê-lo para sua instituição de ensino, as quais têm a autonomia de vender os livros obsoletos devolvidos, sendo o seu valor negociável.

\subsection{Decreto $n^{0}$ 9.373, de 11 de maio de 2018}

O Decreto $\mathrm{n}^{\circ} 9.373$ de 11 de maio de 2018 expõe os critérios para a classificação de bens inservíveis e recomenda descartes ambientalmente adequados.

\section{$[\ldots]$}

Art. $3^{\circ}$ Para que seja considerado inservível, o bem será classificado como:

I - ocioso - bem móvel que se encontra em perfeitas condições de uso, mas não é aproveitado;

II - recuperável - bem móvel que não se encontra em condições de uso e cujo custo da recuperação seja de até cinquenta por cento do seu valor de mercado ou cuja análise de custo e benefício demonstre ser justificável a sua recuperação; 
III - antieconômico - bem móvel cuja manutenção seja onerosa ou cujo rendimento seja precário, em virtude de uso prolongado, desgaste prematuro ou obsoletismo; ou IV - irrecuperável - bem móvel que não pode ser utilizado para o fim a que se destina devido à perda de suas características ou em razão de ser o seu custo de recuperação mais de cinquenta por cento do seu valor de mercado ou de a análise do seu custo e benefício demonstrar ser injustificável a sua recuperação.

$[\ldots]$

Art. $5^{\circ}$ A transferência, modalidade de movimentação de caráter permanente, poderá ser:

I - interna - quando realizada entre unidades organizacionais, dentro do mesmo órgão ou entidade; ou

II - externa - quando realizada entre órgãos da União.

Art. $6^{\circ}$ Os bens móveis inservíveis ociosos e os recuperáveis poderão ser reaproveitados, mediante transferência interna ou externa.

$[\ldots]$

Art. $8^{\circ}$ A doação [...] poderá ser feita em favor:

$[\ldots]$

III - de Organizações da Sociedade Civil de Interesse Público e de associações ou cooperativas que atendam aos requisitos do Decreto $n^{\circ} 5.940$, de 25 de outubro de 2006 , quando se tratar de bem irrecuperável."

Art. $9^{\circ}$ Os alienatários e beneficiários da transferência se responsabilizarão pela destinação final ambientalmente adequada dos bens móveis inservíveis.

$[\ldots]$

(BRASIL. Decreto n ${ }^{\circ} 9.373$, de 11 de maio de 2018)

O descarte proferido no decreto não diz respeito apenas aos livros didáticos, mas sim aos bens públicos em geral. As normas de desfazimento de bens públicos são as mesmas, ou seja, os critérios para o descarte dos livros são os mesmos, todavia, vale recordar que, além das destinações recomendadas pelo decreto acima, existe a possibilidade de realizar a venda - a um valor negociável - dos livros obsoletos, como mencionado no item 2.3 do presente trabalho.

\section{Metodologia}

\subsection{Método}

O presente artigo consiste em um estudo de caso, tendo o intuito de analisar as destinações atribuídas aos estoques obsoletos de duas instituições de ensino médio técnico. Os dados foram coletados entre novembro/2018 e abril/2019 por meio de visitas aos locais de estoque e 
entrevistas, bem como aplicação de questionário a servidores de ambas instituições, de modo a tornar possível a avaliação do material estudado.

O segundo questionário é consoante o Decreto $\mathrm{n}^{\circ}$ 9.373, de 11 de maio de 2018, o qual orienta sobre o descarte ambientalmente correto de bens móveis servíveis e inservíveis. O método utilizado está descrito no Fluxograma 1.

\section{Fluxograma1 - Método utilizado para desenvolvimento do artigo}

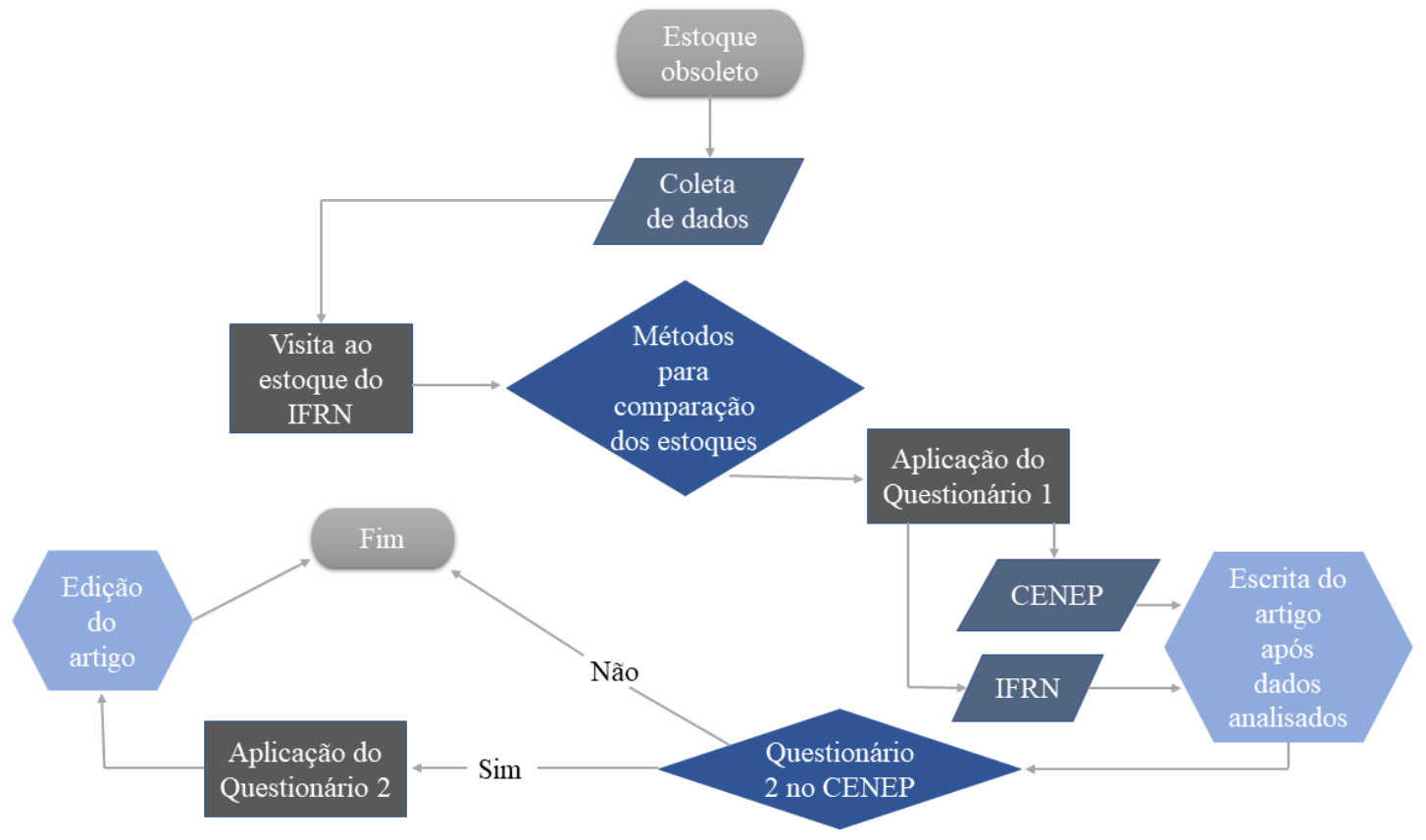

Fonte: Autores (2020).

O descrito fluxograma 1 tem o objetivo de mapear todo o processo de criação do escrito e apresentar os recursos que foram utilizados ao decorrer do artigo.

\subsection{Estudo de caso}

Utilizou-se como estudo de caso o Instituto Federal de Educação, Ciência e Tecnologia do Rio Grande do Norte, campus São Gonçalo do Amarante (IFRN/SGA) e o Centro Estadual de Educação Profissional Senador Jessé Pinto Freire (CENEP). Ambas são instituições de nível médio técnico, sendo a primeira - localizada no bairro Centro, do município de São Gonçalo do Amarante - de propriedade do Governo Federal e a segunda - localizada no bairro Tirol, em Natal - administrada pelo governo estadual.

De acordo com os dados coletados constatou-se a necessidade de um segundo questionário, dessa vez, tratando-se de como ocorreu o desfazimento e seu processo. Fez-se o uso do Decreto $\mathrm{n}^{\circ}$ 9.373, citado anteriormente, servindo como base e orientação da conduta de transferência feita. 


\section{Análise, discussão e resultados}

\subsection{Dados coletados no IFRN}

Segundo o funcionário do IFRN, o material encontra-se armazenado há mais de 1 ano, sem conhecimento do fim que foi dado a uma parcela do lote anterior. Os livros são estocados em um container, sem nenhum tipo de manutenção ou proteção contra avarias. Sua quantidade é desconhecida por ter um volume exorbitante e não ter existido controle quando estavam a receber os livros, mas sabe-se que não houve acréscimos desde o último período de vigência do material.

Houve a possibilidade da doação dos estoques, pois, de acordo com o funcionário entrevistado, existe um espaço apto a receber os estoques de livros do PNLD obsoletos, entretanto a ideia não prosperou. Até o momento da entrevista - que acabou gerando uma conversa sobre o descarte - não havia conhecimento da autonomia que a escola possui para desfazer-se desse tipo de estoque.

\subsection{Dados coletados no CENEP}

Segundo o funcionário da instituição, o estoque de livros do PNLD vinha sendo acumulado há anos e parou de sofrer acréscimo em agosto de 2018, ou seja, havia mais de um lote guardado no interior da escola - especificamente na biblioteca - e teve sua quantidade estabilizada, mesmo desconhecida, desde então.

A escola tomou a iniciativa de realizar uma campanha em redes sociais disponibilizando os livros para que alunos e comunidade os adquirissem por espontaneidade. Diante da baixa procura, o CENEP optou - baseando-se na recomendação do Ministério da Educação - por ceder o material a uma cooperativa de reciclagem.

\subsection{Resultados do primeiro questionário}

As informações postas na Tabela 1 foram declaradas pelos funcionários entrevistados de cada instituição de ensino.

Tabela 1 - Dados coletados nas duas escolas

IFRN

Livros didáticos pertencentes ao PNLD

Tipo de material

obsoleto

Local de

Contêiner
CENEP

Livros didáticos pertencentes ao PNLD

Encontrava-se na biblioteca da 


\begin{tabular}{|c|c|c|}
\hline armazenagem & & instituição \\
\hline Quantidade & Desconhecida & Desconhecida \\
\hline $\begin{array}{c}\text { Tempo de } \\
\text { armazenagem }\end{array}$ & Superior à 1 ano & Superior à 3 anos \\
\hline $\begin{array}{c}\text { Último acréscimo } \\
\text { ao estoque }\end{array}$ & Período de vigência posterior & Agosto/2018 \\
\hline $\begin{array}{l}\text { Conhecimento } \\
\text { sobre descarte }\end{array}$ & $\begin{array}{c}\text { Não havia conhecimento, por parte da } \\
\text { instituição, da autonomia que possui para } \\
\text { o descarte desse tipo de estoque }\end{array}$ & $\begin{array}{l}\text { A instituição teve orientações e foi } \\
\text { recomendada pelo Ministério da } \\
\text { Educação }\end{array}$ \\
\hline $\begin{array}{c}\text { Destinação do } \\
\text { estoque obsoleto }\end{array}$ & $\begin{array}{l}\text { Até o momento, não houve mudanças, isto } \\
\text { é, o material continua guardado no mesmo } \\
\text { local }\end{array}$ & $\begin{array}{l}\text { Cedeu o material a uma cooperativa de } \\
\text { reciclagem, seguindo recomendações do } \\
\text { Ministério da Educação }\end{array}$ \\
\hline
\end{tabular}

Fonte: Desenvolvido pelos autores a partir de dados coletados (2020)

Os livros didáticos do CENEP foram descartados, diferente dos pertencentes ao IFRN, que ainda estão no container. Ambos não souberam responder a quantidade de livros, mas concederam informações acerca do último acréscimo. Apenas o CENEP tinha conhecimento autêntico sobre o descarte, como prova o fato de que apenas este desfez-se do estoque obsoleto, pois seguiu orientações do Ministério da Educação e doou o material a uma cooperativa de reciclagem.

\subsection{CENEP: decreto $n^{0} 9.373$}

Posto que a instituição executou o descarte dos seus livros obsoletos, fez-se mais um questionário, dessa vez baseado no Decreto $\mathrm{n}^{\circ}$ 9.373, de 11 de maio de 2018, com o intuito de analisar a transferência feita.

A tabela a seguir apresenta o questionário baseado no decreto, as questões estão acompanhadas de suas respectivas respostas, as quais foram dadas pelo funcionário da escola. Os artigos selecionados para fundamentar as questões fazem-se presentes no item 2.4 deste escrito.

Tabela 2 - questionário segundo o Decreto n $^{\circ}$ 9.373, de 11 de maio de 2018

\section{Pergunta}

Artigo $3^{\circ}$

Ao estabelecer a necessidade do descarte do material, que critério foi usado para o desfazimento?

Artigo $5^{\circ}$ e $6^{\circ}$
A movimentação interna do material realiza-se

\section{Resposta}

Segundo as normativas do MEC, o período de vigência dos livros é de 3 anos. Sendo assim, passados os 3 anos, esses livros não servem mais. Então, o desfazimento se dá por eles serem considerados irrecuperáveis.

Sabia-se dessa possibilidade de 


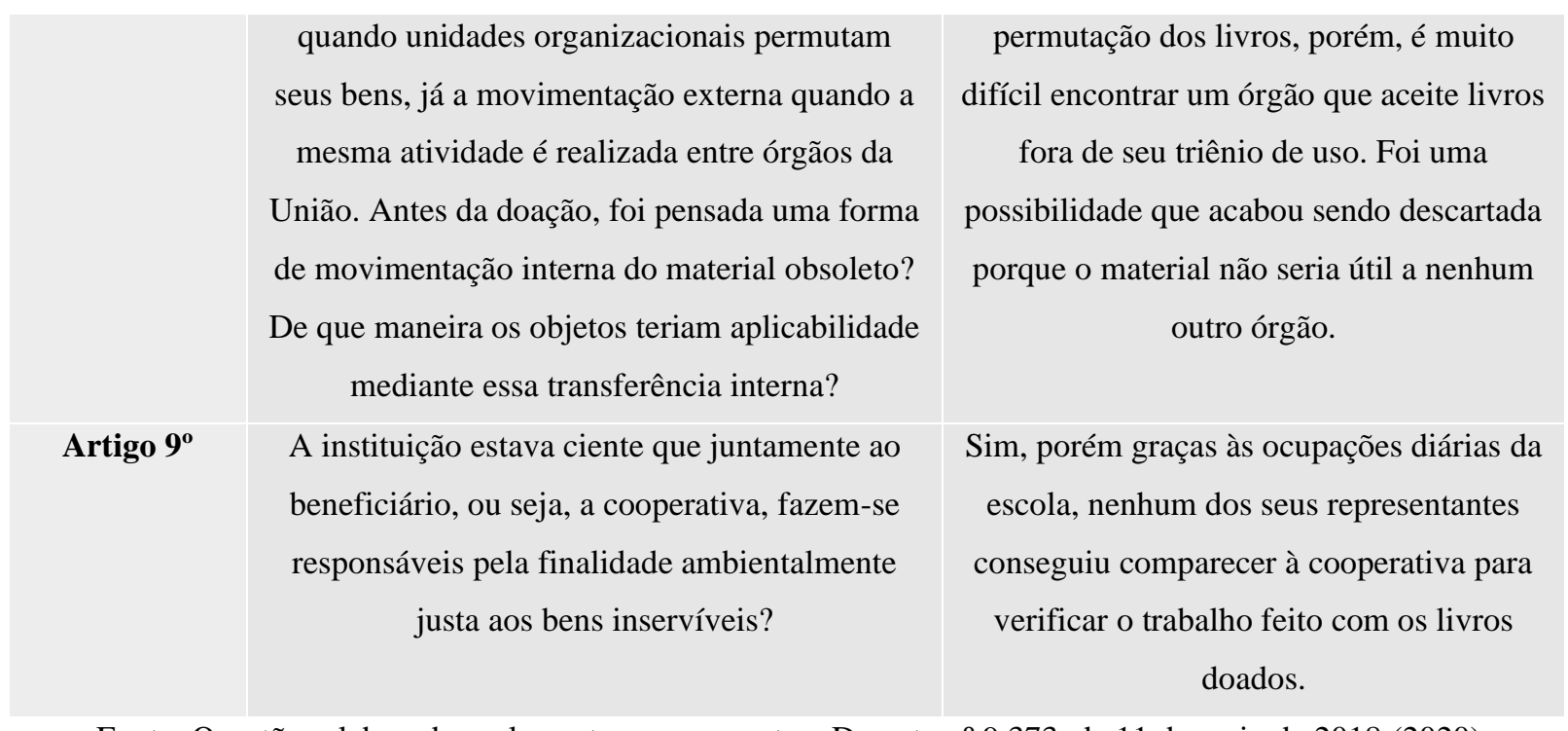

Fonte: Questões elaboradas pelos autores consoante o Decreto ${ }^{\circ}$ 9.373, de 11 de maio de 2018 (2020).

Além dos dados apresentados na tabela, constatou-se que a instituição cumpriu indiretamente, pois de acordo com o funcionário, a escola não tinha conhecimento - a norma prevista no inciso III do $\S 1^{\circ}$ do art. $8^{\circ}$ do decreto em questão.

Com base nos dados obtidos por meio dos questionários, pôde-se constatar que a instituição CENEP expressou resultados de competência superior aos apresentados pelo IFRN, considerando o fato de que somente a primeira enquadrou-se nos parâmetros descritos na legislação que foi utilizada como ferramenta para formular o estudo. Seguindo o previsto na norma, o CENEP teve a iniciativa de promover uma destinação adequada ao acúmulo inservível de livros, de modo a atribuir uma finalidade aos livros obsoletos.

\section{Conclusão}

No presente trabalho foi apresentada a importância de se ter um estoque, bem como as possíveis inconveniências - como a obsolescência, tema central deste - que se há em mantêlo. Por meio de estudo de caso, buscou-se a análise e comparação dos estoques de livros obsoletos de duas instituições de ensino (CENEP e IFRN/SGA), tendo por justificativa a falta de atenção que existe nas instituições para com esse tipo de estoque. Com base no que foi apresentado, concluiu-se que a destinação, recomendada por legislação, tanto é possível quanto necessária, pois, como já foi exposto, um estoque obsoleto é antieconômico, ocupa um espaço que poderia ser utilizado para fins produtivos - como exemplo, pode-se citar a própria biblioteca do CENEP, a qual encontrava-se intransitável e logo após a doação tornou-se um lugar harmonioso - além de necessitar de manutenções. 
Ao encontrar uma finalidade adequada para o material obsoleto, pode-se ter, inclusive, geração de capital ou a economia deste, pois como já foi dito, todo estoque - seja ele obsoleto ou não - tem um custo. 


\section{REFERÊNCIAS}

ALMEIDA, Beth. O que fazer com os livros antigos do PNLD. Disponível em:

http://portal.mec.gov.br/ultimas-noticias/211-218175739/1649-sp-648788579 Acesso em: 03 nov. 2018.

BRASIL. Ministério da Educação. A complexa logística de distribuição dos livros didáticos, desde as editoras até os estudantes. Disponível em: http://portal.mec.gov.br/busca-geral/211-noticias/218175739/74171a-complexa-logistica-de-distribuicao-dos-livros-didaticos-desde-as-editoras-ate-os-estudantes. Acesso em: 03 mai. 2019.

BRASIL. Decreto n ${ }^{\circ}$ 9.373, de 11 de maio de 2018. Dispõe sobre a alienação, a cessão, a transferência, a destinação e a disposição final ambientalmente adequadas de bens móveis no âmbito da administração pública federal direta, autárquica e fundacional. Diário Oficial da União: Seção 1, Brasília, DF, p. 1. Disponível em: http://www.planalto.gov.br/ccivil_03/_Ato2015-2018/2018/Decreto/D9373.htm. Acesso em: 02 mai. 2019.

BRASIL. Ministério da Educação. O MEC distribui livros didáticos para todas as escolas do país?

Disponível em: http://portal.mec.gov.br/component/content/article?id=158:o-mec-distribui-livros-didaticos-paratodas-as-escolas-do-pais. Acesso em: 08 nov. 2018.

BRASIL. Mistério da Educação. O que fazer com os livros antigos do PNLD. Disponível em: http://portal.mec.gov.br/index.php?option=com_content\&view=article\&id=1649:sp648788579\&catid=211\&Itemid=86. Acesso em 03 mai. 2019

BRASIL. Ministério da Educação. PNLA - Funcionamento. Disponível em: http://portal.mec.gov.br/buscageral/314-programas-e-acoes-1921564125/pnla-1777900200/12381-pnla-funcionamento Acesso em: 08 nov. 2018.

HÖFLING, Eloisa de Mattos et al. Notas para discussão quanto à implementação de programas de governo: em foco o Programa Nacional do Livro Didático. Educação \& Sociedade, 2000.

POZO, H. Administração de recursos materiais e patrimoniais: uma abordagem logística. São Paulo: Atlas, 2010 .

SLACK, N: CHAMBERS, S; JOHNSTON, R. Administração da Produção. Atlas, São Paulo, 2009.

TSESTOQUE. Definição de políticas para o controle de estoque. Disponível em: <http://universidadeestoque.com.br/blog/index.php/definicao-de-politicas-para_o_controle_de-estoque/> Acesso em: 14 nov. 2018. 